\title{
Promoting Leapfrog Development in Underdeveloped Areas Through Institutional Culture Innovation
}

\author{
Xinyou Liu ${ }^{1}$ and Jiaoyan Tang ${ }^{2, *}$
}

\author{
${ }^{1}$ Kunming Branch, Water Diversion Engineering Construction Administration for Central Yunnan, Kunming, 650000, \\ China \\ ${ }^{2}$ College of Humanities and Arts, Yunnan Communications Vocational and Technical College, Kunming, 650500, China \\ *Corresponding author e-mail: 503687348@qq.com
}

\begin{abstract}
Promoting leapfrog development in underdeveloped areas is the primary task of socialist construction. Therefore, it is of immense significance to analyze the practical ways to realize leapfrog development in underdeveloped areas. From the perspective of the positive and causal feedback relationship between regional culture and regional development, it is concluded that institutional culture plays a core role in regional culture, and institutional culture innovation in underdeveloped areas has a good foundation. Consequently, it is a realistic way to exploring and giving full play to the enthusiasm and creativity of citizens in underdeveloped areas to participate in the innovation of institutional culture through the leading role of government and social elite.

Keywords: Institutional culture; Regional culture; Regional development; Underdeveloped areas
\end{abstract}

\section{INTRODUCTION}

While the socialist construction of China has made great achievements, the regional gap is also expanding, which has become the stumbling block of "building a harmonious socialist society". Therefore, the regional development strategy and development practice aimed at building a harmonious society will always be faced with the arduous task of how to accelerate the leapfrog development of underdeveloped areas and realize the harmonious development of all ethnic groups and regions in the whole country for a long time in the future. It is necessary to rely on innovation to achieve leapfrog development in underdeveloped areas. The General Secretary Xi Jinping points out that innovation is a systematic project. and the innovation, industrial, capital and policy chains are interwoven and mutually supportive. It is not enough carrying out reform only in one or several links. It must be implemented across the board. It is also necessary to unswervingly promote scientific and technological innovation and institutional innovation to play a coordinated role and turn the two wheels together [1]. Institutional innovation is the integration of social order, which needs more guidance from a cultural concept with subject value. Social cultural identity is a kind of flexible restriction on social order, and subject culture, as spiritual resources, will play a profound role in the social public sphere, which is long-lasting [2]. Culture is a kind of pattern manifestation of human mental state and thought structure, and the designer of the system is the executor of culture [3]. The culture breeds the system, and the system chooses the culture. The political society has its own logic, and the institutional culture often becomes a kind of "path dependence" of political, economic and social transformation [4]. Therefore, it is a realistic way to realize the leapfrog development of the underdeveloped areas to promote the political, economic and social reform through the institutional culture innovation. Through analyzing the relationship between regional culture and regional development, the role of institutional culture in regional culture, the basis of institutional culture innovation in underdeveloped areas, and the practical ways of institutional culture innovation in underdeveloped areas, it is helpful to clarify the logical relationship between institutional culture innovation and leapfrog development in underdeveloped areas, strengthen institutional culture confidence, and point out a feasible path for the underdeveloped areas to realize leapfrog development.

\section{RELATIONSHIP BETWEEN REGIONAL CULTURE AND REGIONAL DEVELOPMENT}

Under the influence of geographical location and development foundation, the imbalance of regional development in China is especially prominent. From the perspective of "economic foundation and its superstructure", the imbalance is mainly manifested in first, the imbalance of economic development, such as the gap between the east and the west of China; second, the imbalance of cultural development, which has a certain relationship with economic development and historical cultural differences. From the perspective of "human-land relationship regional system", the imbalance is mainly manifested first, the imbalance between different regions, which is also obvious in the east and west of China; 
second, the imbalance between regions. For example, in Yunnan Province, the development of other regions is obviously underdeveloped except for Kunming City, which is a supercity. The regional imbalance of these two angles has seriously restricted the development of harmonious society in underdeveloped areas.

The overall level of regional development can be investigated from aspects of the regional economic development level and the regional cultural development level. A large number of theoretical and regional practical studies show that "regional overall development level" has a positive causal feedback relationship with "economic development level" and "cultural development level" of the region respectively: first, the "overall regional development level" and "regional economic development level" promote or drag down each other; second, the "regional overall development level" and "regional cultural development level" promote each other or drag each other down.

For western underdeveloped regions, the direct regional economic leapfrog development only depends on a large number of external investments. However, under the reality of limited national investment, marketization of capital operation and lower investment rate of return than the eastern developed areas, it is difficult for the underdeveloped areas to attract a large number of external investments, which makes it almost impossible for these areas to realize direct economic leapfrog development. However, with the support of highly developed transportation and information circulation, regional culture can achieve leapfrog development, that is, the speed and level of development of regional culture can exceed that of regional economy and the whole region. Through the improvement of regional cultural level, the "overall regional development level" will also be greatly improved due to the effect of its positive causal feedback relationship, and the "regional overall development level" will be greatly improved. Then a positive causal feedback relationship of "regional overall development level, regional economic development level and regional cultural development level" can be formed. Therefore, the leapfrog development of regional culture is a feasible way to promote the underdeveloped areas to achieve leapfrog development.

\section{THE CENTRAL ROLE OF INSTITUTIONAL CULTURE IN REGIONAL CULTURE}

Corresponding to human's activities of adapting and transforming nature, society and human beings, culture can be divided into categories of material culture, institutional culture and spiritual culture. Material culture is the result of human activities to transform nature, which generally refers to the ability to transform nature and its labor products, mainly including productivity, production tools and articles for daily use. Institutional culture is the result of human activities to transform society, mainly including social production relations, social system, organizational form and social behavior norms. Spiritual culture is the result of human activities to transform themselves, mainly including scientific culture, people's life style, values, thinking mode and psychological state.

How to truly understand the Chinese system and the Chinese cultural genes immersed in it is inseparable from the correct understanding and in-depth understanding of Chinese history and excellent traditional Chinese culture [5]. The level of cultural development of a region in different periods, the level of cultural development of different regions in the same period and the level of cultural development of different regions in different periods can be measured from aspects of material culture, institutional culture and spiritual culture. A large number of theoretical research and practical research on regional cultural development show that the "level of regional cultural development" in underdeveloped areas has a positive causal feedback relationship with the "material culture development level", "system culture development level" and "spiritual culture development level" respectively.

In the cultural development of underdeveloped areas, regional institutional cultural innovation should be taken as the core of the whole regional cultural construction. There are two main practical reasons: first, since the direct promotion of regional material culture should be supported by a solid material foundation, but the regional spiritual culture has a strong historical inheritance, both of which are difficult to achieve direct leapfrog development. Although the regional system culture is also restricted by the social development, for a certain region, its regional institutional culture has a certain flexibility, and can achieve leapfrog development in a relatively short period of time. Second, most of the underdeveloped areas are ethnic areas, and the ethnic cultural diversity is particularly prominent. In contrast, their institutional culture is relatively single, and there is no corresponding innovation mechanism. Therefore, the innovation of regional institutional culture suitable for national cultural diversity will play an extremely important role in the development of regional culture. The development of regional culture in the future will depend to a great extent on the development of regional institutional culture. That is to say, as long as the level of regional institutional culture development can be continuously improved, the level of material and cultural development, the level of spiritual and cultural development and the level of cultural development of the whole region can be constantly improved through the mechanism of a benign positive causal feedback relationship, then the development of underdeveloped areas can be promoted, and the gap between different regions can be narrowed, so as to achieve regional coordinated development. For example, the underdeveloped areas can create a favorable environment for innovation, entrepreneurship and living through efficient government services, preferential tax policies, elaborate counterpart assistance, specialized social services and spiritual care, thus promoting the development of the whole region. 
In fact, China's socialist reform and opening up is to promote the development of the whole social culture through the reform of the economic system, and then achieve the goal of the development of the whole country through the positive and causal feedback mechanism of "national cultural development-national economic development-national development". The brilliant achievements of China's socialist reform and opening are enough to prove the theoretical correctness of the above analysis and the practical feasibility of practice.

\section{FOUNDATIONS OF INSTITUTIONAL CULTURAL INNOVATION IN UNDERDEVELOPED AREAS}

The way to form institutional confidence is to carry out institutional innovation, promote institutional innovation with theoretical innovation, and promote the modernization of national governance ability with scientific and systematic modern institutional system [6]. Institutional culture can be divided into two levels: one is the institutional culture at the national level, that is, the overall social relations of production, the social system, the organizational form of the whole country, the laws and regulations formulated uniformly by the state; the other is the institutional culture at the regional level, that is, the social relations of production, the social system, the organizational form, the local laws and regulations formulated according to the regional reality on the basis of the institutional culture at the national level. The development of institutional culture at the national level is influenced by the regions, and its overall promotion needs a long historical process, which can not be directly controlled by a single region. Therefore, based on regional realities, the underdeveloped areas should adhere to the innovation of social governance, explore the regional institutional culture suitable for the regional social and economic development, and improve the level of regional institutional culture within the scope of regional authority through the joint efforts of government departments and regional elites.

The improvement of regional system culture level is necessary and conditional. First, the institutional and cultural innovation that meets the actual social development needs of the region is necessary. The institutional culture at the national level is formulated on the basis of the overall social development of the whole country and serves the whole country, but this does not mean that the institutional culture at the national level covers every field in each region, therefore, it needs to be further refined by each region according to its own actual situation. Second, the government encourages innovation in social governance. No matter at the national level or at the regional level, the construction of institutional culture revolves around the promotion of all-round and coordinated economic and social development and the construction of a harmonious society. Therefore, as long as the regional institutional and cultural innovation is carried out around the above purposes, it is encouraged by the state, which provides the political legitimacy and practical basis for the regional institutional and cultural innovation. Third, the source of regional institutional cultural innovation is abundant. China is a multinational country, and the system of regional ethnic autonomy has safeguarded national unity and ethnic unity, guaranteed the equal rights of ethnic minorities, promoted the economic development of ethnic areas, and played an important role in the construction of a harmonious socialist society [7]. Therefore, it is of great practical significance to carefully study the evolution of special policies in ethnic minority areas and adopt a positive attitude to ensure the continuity, stability and effectiveness of special policies [8]. In the ethnic minority areas, the long-term special policies of ethnic areas and the village regulations and folk agreements contain a very rich institutional culture in line with the actual situation of the region, which can provide rich materials and experience for the innovation of regional institutional culture. In recent years, it has played an important role in grass-roots governance by strengthening institutional and cultural construction and eliminating the negative effects of traditional institutions and cultures [9]. Regional institutional and cultural innovation involves many aspects, such as social relations of production, social system, organizational forms and norms of social behavior. The cultural quality of the common people in the underdeveloped areas is generally low, the cultural background is very different, and the consciousness of institutional cultural innovation and the participation ability of institutional cultural innovation are relatively limited. Therefore, the regional institutional cultural innovation under the guidance of the government and social elites is the fastest, most effective and the lowest cost, which is the first choice for the rapid improvement of the regional institutional cultural level.

\section{THE REALISTIC APPROACH OF INSTITUTIONAL CULTURE INNOVATION IN UNDERDEVELOPED REGIONS}

China is an all-around open country, and its institutional construction and rule of law construction are also carried out under such an open environment, therefore, it can learn from all the beneficial achievements of human civilization [10]. The advantages of the socialist system with Chinese characteristics are the fundamental guarantee for promoting economic and social development, and also provide an inexhaustible source for regional institutional and cultural innovation. The innovation of regional system culture should adhere to the combination of theory and practice, and take reducing the cost of social governance, integrating social governance resources, meeting the needs of the public, promoting the overall and coordinated development of economy and society, constructing a harmonious society, and coordinating the development of urban and rural areas as the fundamental starting point and 
foothold of regional system culture innovation. It is particularly important for underdeveloped areas to study the rules of regional social development and social governance, strengthen inter-regional exchanges and cooperation, learn from the successful experience of regional system and culture at home and abroad, and take the road of system and culture innovation suitable for the development of the region from the actual situation of the region.

The innovation of regional institutional culture should be based on administration according to law and guarantee social justice. Only by bringing regional public power into the track of rule of law, making it legal, reasonable, efficient and convenient, and unifying power and responsibility, can it reduce the cost of social governance continuously and realize good social governance. At the same time, only by straightening out the social distribution relationship, rationally adjusting the pattern of national income distribution, correctly handling the relationship between fairness and efficiency, and striving to create a fair and just social environment from the aspects of law, system and policy, can all aspects of social relations be coordinated, and people's enthusiasm, initiative and creativity can be brought into full play.

The innovation of regional institutional culture should improve the quality of public servants and expand citizen participation. Through the innovation of diversified system, it can adapt to the social change and break through the restriction of system and culture, and get the situation of "win-win" of government, enterprise and local community [11]. The behavior of government has a model effect on the behavior of citizens, and it is necessary to transform government functions and enhance government image in order to strengthen the system of regional culture reform and innovation. For example, it is necessary to improve the awareness and ability of law-based administration, public services, crisis management and overall coordination, and place government actions under public supervision, so as to realize real political democratization. Regional institutional and cultural innovation involves many aspects of society, therefore, government departments can not cover all aspects, and they need the norms of public opinion and social morality, which requires giving full play to the role of regional social elites. Through the leading role of social elites, the enthusiasm and creativity of citizens in participating in institutional cultural innovation are constantly explored and brought into play.

\section{CONCLUSION}

The practice of socialist reform and opening up in China profoundly shows that through the improvement of regional system culture innovation level, "the level of regional cultural development", "the level of regional material and cultural development" and "the level of regional spiritual and cultural development" will be greatly improved because of its benign positive causal feedback effect. At the same time, the "level of regional cultural development" will be greatly improved because of its benign positive and causal feedback, and the "level of regional overall development" and "level of regional economic development" will also be greatly improved. This is the desired vision for the better development of underdeveloped areas. Such a vision indicates that the future development of underdeveloped areas will be continuously optimized in the process of self-organization of regional development and other organizational processes, thus narrowing the gap between them and developed areas, and laying a solid foundation for strengthening the confidence of system and culture and realizing the development of harmonious society in the whole country and underdeveloped areas.

\section{ACKNOWLEDGMENT}

This work is supported by "Ten-thousand Plan" of Yunnan Top Young Talents (No. YNWR-QNBJ-2019-067) and Science Research Fund of Yunnan Education Department (No. 2020J1015).

\section{REFERENCES}

[1] Xi Jinping. Striving to Build a World Power in Science and Technology [M]. Beijing: People's Publishing House, 2016: 13-14.

[2] Hou Dongmei. Construction of Subjectivity Culture in the System of Social Integration [J]. Theory Research, 2015 (36): 98-99.

[3] Chai Baoyong, Li Tian. Between "New Type" and "Tradition": Analysis of the traditional Cultural Factors Affecting the New Political Party System in China [J]. Socialist Studies, 2019 (5): 82-89.

[4] Zhang Xishan. Construction of Contemporary Chinese Institutional Culture: Significance and Direction [J]. Contemporary Chinese Political Research Report, 2015: 226-237.

[5] Liu Yuli. Cultural Genes of Chinese System [P]. Study Times, 2020-12-28.

[6]Zhang Huaizhong. Research on the Formation Basis and Strengthening Path of Confidence in Socialist System with Chinese Characteristics [J]. Journal of Henan Judicial Police Vocational College, 2020, 18 (04): 112-116.

[7] Li Ziyuan. The System of Regional Ethnic Autonomy in China and the Construction of Harmonious Society [J]. Guangxi Ethnic Studies, 2006 (3): 7-11. 
[8] Special Policy Research Group in Ethnic Areas. Review of the Evolution of Special Policies in Yunnan Ethnic Regions [J]. Ethnic Work, 1997 (6): 21-26.

[9] Chen Ya. Villagers' Participation Mechanism in Grass-roots Governance in China: Evolution Watershed and Promotion Path - Taking Longyan City, Fujian Province as an Example [J]. Economist, 2020 (12): 25-27.
[10] Tao Wenzhao. Will the History and Culture Drag Down the Construction of Institutions [P]. People's Daily, January 28, 2015, Edition 007.

[11] Gao Boyang, Liu Weidong, Song Tao, et al. "Multi-scale Embeddedness" Under Social Change and Institutional Culture - Taking the Laibitang Copper Mine Project in Myanmar as an Example [J]. Geography Studies, 2020, 39 (12): 2718-2730. 